Author affiliations and support information (if applicable) appear at the end of this article.

Published at jco.org on June 12, 2017.

Clinical trial information: NCT01555710.

Corresponding author: Shadia I. Jalal, MD, Indiana University Melvin and Bren Simon Cancer Center, 980 W Walnut St, Indianapolis, IN 46202; e-mail: sjalal@ iupui.edu.

(C) 2017 by American Society of Clinical Oncology

0732-183X/17/3523w-2619w/\$20.00

\section{ASSOCIATED CONTENT}

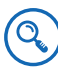

Appendix

DOI: https://doi.org/10.1200/JCO 2016.71.7454

(2) Data Supplement DOI: https://doi.org/10.1200/JCO 2016.71.7454

DOI: https://doi.org/10.1200/JCO.2016. 71.7454

\title{
Carboplatin and Etoposide With or Without Palifosfamide in Untreated Extensive-Stage Small-Cell Lung Cancer: A Multicenter, Adaptive, Randomized Phase III Study (MATISSE)
}

Shadia I. Jalal, Philip Lavin, Gregory Lo, Francois Lebel, and Lawrence Einhorn

$$
\begin{array}{llllllll}
\text { A } & \text { B } & \text { S } & \text { T } & \text { R } & \text { A } & \text { C } & \text { T }
\end{array}
$$

\section{Purpose}

To evaluate the efficacy of the addition of palifosfamide to carboplatin and etoposide in extensive stage (ES) small-cell lung cancer (SCLC).

\section{Patients and Methods}

MATISSE was a randomized, open-label, adaptive phase III study. Previously untreated patients with ES SCLC were randomly assigned in a 1:1 fashion to receive carboplatin at area under the serum concentration-time curve 5 on day 1 plus etoposide $100 \mathrm{mg} / \mathrm{m}^{2}$ per day on days 1 to 3 every 21 days (CE) or carboplatin at area under the serum concentration-time curve 4 on day 1 plus etoposide $100 \mathrm{mg} / \mathrm{m}^{2}$ per day plus palifosfamide $130 \mathrm{mg} / \mathrm{m}^{2}$ per day on days 1 to 3 every 21 days (PaCE). The primary end point was overall survival.

\section{Results}

In all, 188 patients were enrolled; 94 patients received CE and 94 patients received PaCE. The median age on both arms was 61 years. Six cycles of chemotherapy were completed on both arms of the study by approximately $50 \%$ of the patients. Serious adverse events were documented and did not differ significantly between patients receiving $\mathrm{PaCE}$ and those receiving $\mathrm{CE}$. Median overall survival was similar between both arms with 10.03 months on $\mathrm{PaCE}$ and 10.37 months on CE $(P=.096)$.

\section{Conclusion}

The addition of palifosfamide to CE failed to improve survival in ES SCLC.

J Clin Oncol 35:2619-2623. (C) 2017 by American Society of Clinical Oncology

\section{INTRODUCTION}

Platinum doublet chemotherapy has been the standard of care first-line regimen in patients with extensive stage (ES) small-cell lung cancer (SCLC) for the last three decades. ${ }^{1}$ Cisplatin in combination with irinotecan is the more frequently used regimen in Japan, but cisplatin with etoposide or carboplatin with etoposide (CE) is used in the United States. ${ }^{2}$ Objective response rates in the first-line setting are $67 \%$ to $80 \%$, and median overall survival (OS) is 8 to 13 months. ${ }^{3}$ Unfortunately, disease relapse occurs in all patients, and second-line chemotherapy options lead to short responses. ${ }^{4}$ Novel first-line therapies continue to be urgently needed.

A previous Hoosier Oncology Group phase III study demonstrated an improvement in OS with the addition of ifosfamide to cisplatin and etoposide. ${ }^{5,6}$ Ifosfamide, an alkylating agent, in combination with cisplatin and etoposide (VIP) increased median OS to 9 months compared with 7.3 months with cisplatin and etoposide alone. In addition, the 2-year OS was improved from 5\% to $13 \%$ in favor of VIP. However, the increased toxicity and inconvenience of the addition of ifosfamide, including the need for hospitalization and intravenous fluids, precluded the adoption of VIP as the standard first-line regimen for the treatment of ES SCLC. Ifosfamide is a prodrug whose cytotoxic effects are largely exerted by its active metabolite isophosphoramide mustard. ${ }^{6}$ However, the clinical utility of ifosfamide is limited by a number of toxic metabolites such as acrolein and chloracetaldehyde, which are associated with hemorrhagic cystitis and neurotoxicity, respectively. 
Palifosfamide (Zymafos, ZIO-201; ZIOPHARM Oncology, Boston, MA) is a salt formulation of isophosphoramide mustard, the active metabolite of ifosfamide that was developed by ZIOPHARM Oncology. ${ }^{7,8}$ Preclinical activity demonstrated that palifosfamide was active in a number of tumor models, including sarcoma and lung cancer. ${ }^{9}$ Palifosfamide was previously combined with CE in a phase I trial in patients with advanced solid malignancies. ${ }^{10}$ Carboplatin at an area under the serum concentrationtime curve (AUC) 4 on day 1 combined with etoposide at $100 \mathrm{mg} / \mathrm{m}^{2}$ on days 1 to 3 and palifosfamide at 100,130 , or $150 \mathrm{mg} / \mathrm{m}^{2}$ on days 1 to 3 were evaluated for safety in a standard $3+3$ dose-escalation design. The dose-limiting toxicity reported was febrile neutropenia. Carboplatin at an AUC of 4 on day 1, etoposide at $100 \mathrm{mg} / \mathrm{m}^{2}$ on days 1 to 3 , and palifosfamide at $130 \mathrm{mg} / \mathrm{m}^{2}$ on days 1 to 3 was shown to be a safe combination. By using that dosing schedule, we conducted a trial that evaluated the addition of palifosfamide to CE in patients with untreated ES SCLC.

\section{PATIENTS AND METHODS}

Eligible patients had histologic or cytologic diagnosis of ES SCLC defined as disease beyond the ipsilateral hemithorax, including contralateral mediastinum in the supraclavicular area and malignant pleural or pericardial effusion or hematogenous spread. Eligibility criteria included Eastern Cooperative Oncology Group performance status (ECOG PS) of 0 to 2 . No prior chemotherapy or radiotherapy was allowed except prior radiotherapy for brain metastases as long as the patient had recovered from all acute radiation-related toxicities. Adequate bone marrow (hemoglobin $\geq 10.0 \mathrm{~g} / \mathrm{dL}$, absolute neutrophil count $\geq 1,500 / \mu \mathrm{L}$, platelet count $\geq 100,000 / \mu \mathrm{L}$ ), liver (total bilirubin $\leq 1.5 \times$ upper limit of normal, ALT and AST $\leq 2.5 \times$ upper limit of normal or $\leq 5$ if documented liver metastases), and renal function (estimated glomerular filtration rate $\geq 60 \mathrm{~mL} / \mathrm{min}$ per
$1.73 \mathrm{~m}^{2}$ ) were required. Patients were defined as active smokers if they had smoked 100 cigarettes in their lifetime and continue to smoke, former smokers if they currently do not smoke, and never smokers if they have never smoked or have smoked fewer than 100 cigarettes in their entire lifetime. Patients were excluded if they had significant concurrent medical conditions that would impact the safety of the patient or if they had a clinically significant infection within 7 days of random assignment. In addition, patients were excluded if they had symptomatic, untreated brain metastases but were allowed if their brain metastases were asymptomatic. Each patient signed an institutional review board-approved, protocol-specific informed consent in accordance with institutional guidelines (Fig 1).

\section{Study Treatments}

A minimum of four and maximum of six cycles were allowed on the trial. The use of growth factors such as erythropoietin or granulocyte colony-stimulating factor was allowed at the discretion of the investigator. Carboplatin was administered at AUC 4 on day 1 , etoposide at $100 \mathrm{mg} / \mathrm{m}^{2}$ on days 1 to 3 , and palifosfamide at $130 \mathrm{mg} / \mathrm{m}^{2}$ on days 1 to 3 every 21 days.

Study design and statistical considerations. MATISSE (Multicenter Adaptive Trial Investigating Small Cell Lung Cancer Survival Endpoints) was a multicenter, multinational, randomized, controlled, open-label phase III trial with an adaptive design. The primary end point of the study was OS defined as the time from random assignment to the date of death. Initial secondary end points included progression-free survival (PFS), objective response rates, duration of response, and safety, including all adverse events (AEs). Tumor-related end points were to be assessed according to Response Evaluation Criteria in Solid Tumors (RECIST 1.1). The study used an adaptive group sequential design that allowed early stopping for efficacy or futility and sample size re-estimation on the basis of the results of the interim analysis. The original sample size was estimated on the basis of 8.4- and 11.2-month median survivals for the control and treatment arms, respectively. Eligible patients were stratified according to age, sex, and ECOG PS and were allocated to treatment in a 1:1 ratio. With one-sided $2.5 \%$ type I error and an O'Brien-Fleming boundary at 0.5 for early efficacy, the power of the trial was $87 \%$. Proportional hazards assumptions were checked by using the Schoenfeld method. On the basis of

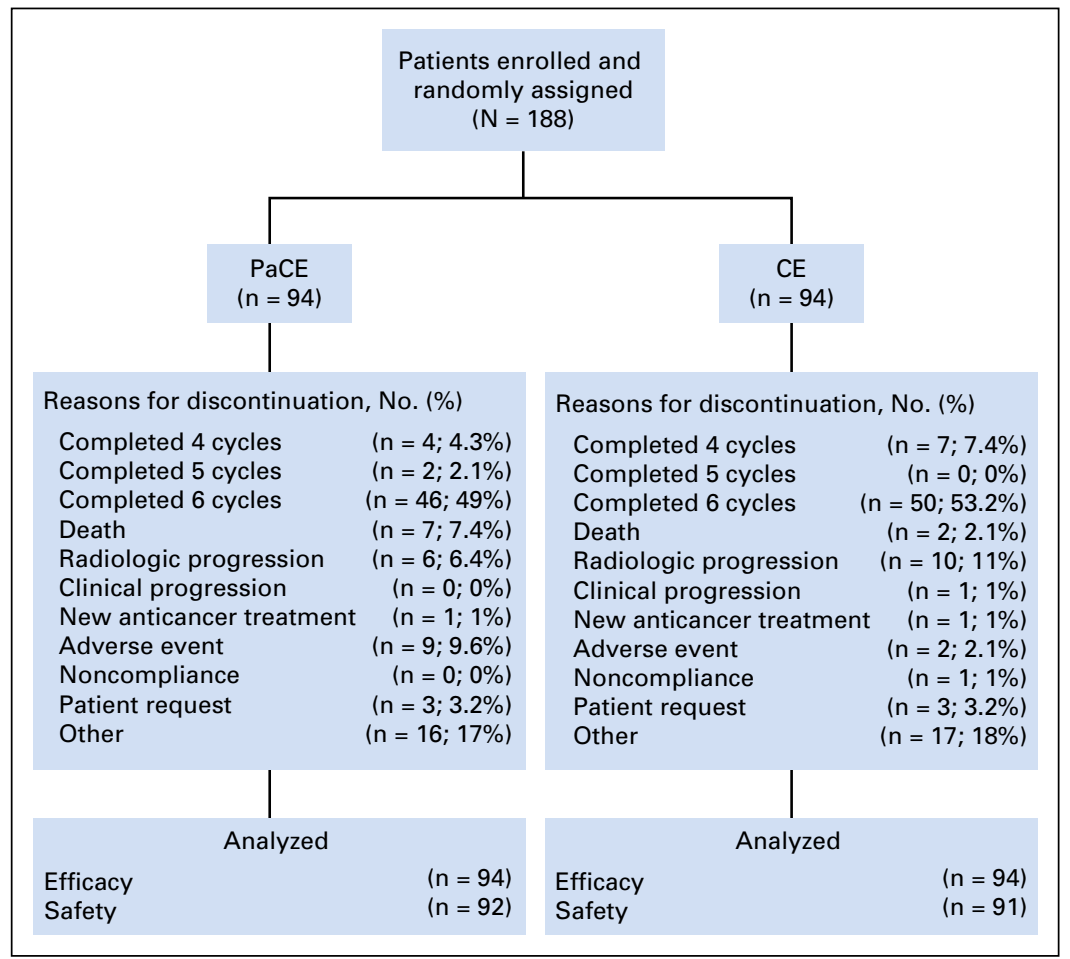

Fig 1. CONSORT diagram. CE, carboplatin and etoposide; $\mathrm{PaCE}$, palifosfamide plus $\mathrm{CE}$. 
the number of events required, the expected number of patients to be enrolled on the study was 464 with a maximum number of 548 patients (274 per arm). The interim analysis by an independent data monitoring committee was planned after 125 OS events. The intention-to-treat population was defined as all randomly assigned patients. The safety population was defined as all randomly assigned patients who were treated with any study therapy. Patients were randomly assigned in a 1:1 ratio by using an interactive response system and were stratified on the basis of age, sex, and initial PS.

The development plans for palifosfamide changed after analysis showed negative phase III data regarding the addition of palifosfamide to doxorubicin in metastatic soft tissue sarcomas. ${ }^{11,12}$ This led to an amendment that closed the study to enrollment after 188 patients of the planned 464 patients were randomly assigned. The primary objective remained OS. The secondary objectives were amended to include serious AEs (SAEs) only as compared with all AEs. An event was considered an SAE if it resulted in death, was life-threatening, required in-patient hospitalization or prolongation of existing hospitalization, was a persistent or significant disability/incapacity, or was a congenital anomaly/birth defect. Treatment-emergent adverse events (TEAEs) were reported and defined AEs that started on or after the date of the first dose of any study drug. The maximum intensity of events was recorded by using the National Cancer Institute Common Terminology Criteria for Adverse Events 4.03. The investigator determined the potential relationship of events to the study drugs. In addition, as part of the amendment, response assessments and PFS were no longer required. The amended statistical post hoc power was $80 \%$ and a twosided 0.05 type I error was used to detect a 0.64 hazard ratio (HR) in OS with 94 patients on each treatment arm observed for up to 40 months.

\section{RESULTS}

\section{Patient Characteristics}

This study was a multicenter, multinational study that enrolled patients in 13 countries and 70 (of 109) study sites. From June 8, 2012, through April 22, 2013, 188 patients were randomly assigned ( 94 per arm). Among the 188 patients randomly assigned, there were 159 deaths; 29 patients were alive at the time of this analysis. The last patient follow-up was performed on December 2, 2014. Baseline characteristics of patients are summarized in Table 1 with no major differences between arms. Median age on both arms was 61 years, with $70 \%$ of patients being males as is expected in SCLC. Two thirds of patients were treated outside the United States with Russia enrolling the most patients outside the United States, followed by Ukraine and France. Sixty patients were treated in the United States, five in Australia, 14 in Canada, 15 in France, one in Germany, three in Hungary, and five each in Israel, Italy, and Poland, 45 in Russia, three in Taiwan, 17 in Ukraine, and 10 in the United Kingdom (for a list of all study sites, see Appendix Table A1 [online only]). All 188 patients were evaluable for OS and were included in the intention-to-treat population. Because of the amendment, response assessments were left to the discretion of investigators and were collected in only $45 \%$ of patients on each treatment arm.

\section{Treatment Delivered}

Approximately half the patients on each arm received six cycles of chemotherapy. The main reason for death was disease

\begin{tabular}{|c|c|c|c|c|}
\hline \multirow[b]{2}{*}{ Characteristic } & \multicolumn{2}{|c|}{$\begin{array}{c}\text { PaCE } \\
(n=94)\end{array}$} & \multicolumn{2}{|c|}{$\begin{array}{c}C E \\
(n=94)\end{array}$} \\
\hline & No. & $\%$ & No. & $\%$ \\
\hline Median age, years (range) & \multicolumn{2}{|c|}{$61(42-82)$} & \multicolumn{2}{|c|}{$61(32-88)$} \\
\hline \multicolumn{5}{|l|}{ Sex } \\
\hline Male & 66 & 70 & 66 & 70 \\
\hline Female & 28 & 30 & 28 & 30 \\
\hline \multicolumn{5}{|l|}{ ECOG PS } \\
\hline 0 & 24 & 25 & 21 & 22 \\
\hline 1 & 60 & 64 & 62 & 66 \\
\hline 2 & 10 & 11 & 9 & 10 \\
\hline \multicolumn{5}{|l|}{ Metastases } \\
\hline Liver & 39 & 42 & 37 & 39 \\
\hline Brain & 14 & 15 & 17 & 18 \\
\hline Bone & 14 & 15 & 16 & 17 \\
\hline \multicolumn{5}{|l|}{ Country } \\
\hline US & 31 & 33 & 29 & 31 \\
\hline Other & 63 & 67 & 65 & 69 \\
\hline \multicolumn{5}{|l|}{ Smoking status } \\
\hline Current & 46 & 49 & 44 & 47 \\
\hline Former & 36 & 38 & 33 & 35 \\
\hline Unknown & 7 & 7.4 & 10 & 10.6 \\
\hline Never & 5 & 5.3 & 7 & 7.4 \\
\hline
\end{tabular}

progression in $82 \%$ of patients on either the CE or PaCE arm. Dose delays and reductions were not collected from enrolling sites.

\section{Toxicity}

The safety population included 92 patients on the PaCE arm and 91 patients on the CE arm; five patients were not evaluable for toxicity. Safety population patients had received at least one dose of the study therapy. There were no significant differences between the two treatment arms in the number of patients who experienced SAEs $(P>.99)$. Twenty-six patients $(28.3 \%)$ on the PaCE arm and 25 patients $(27.5 \%)$ on the CE arm had at least one SAE as defined per protocol. SAEs reported in three or more patients on either arm are listed in Table 2. Approximately $20 \%$ of patients on both treatment arms experienced at least one TEAE. Dizziness was the

\begin{tabular}{|c|c|c|c|c|}
\hline \multirow[b]{2}{*}{ Toxicity } & \multicolumn{2}{|c|}{$\begin{array}{c}\text { PaCE } \\
(n=92)\end{array}$} & \multicolumn{2}{|c|}{$\begin{array}{c}\text { CE } \\
(n=91)\end{array}$} \\
\hline & No. & $\%$ & No. & $\%$ \\
\hline \multicolumn{5}{|l|}{ Hematologic } \\
\hline Febrile neutropenia & 4 & 4.3 & 5 & 5.5 \\
\hline Pancytopenia & 4 & 4.3 & 0 & 0 \\
\hline Neutropenia & 1 & 1.1 & 3 & 3.3 \\
\hline Nausea & 3 & 3.3 & 1 & 1.1 \\
\hline Dehydration & 3 & 3.3 & 2 & 2.2 \\
\hline Hyponatremia & 0 & 0 & 3 & 3.3 \\
\hline Dyspnea & 3 & 3.3 & 2 & 2.2 \\
\hline Infection & 5 & 5.4 & 9 & 9.9 \\
\hline $\begin{array}{l}\text { Abbreviation: CE, ca } \\
\text { serious adverse ever }\end{array}$ & and e & $\mathrm{PaCE}$ & amide & SAE \\
\hline
\end{tabular}




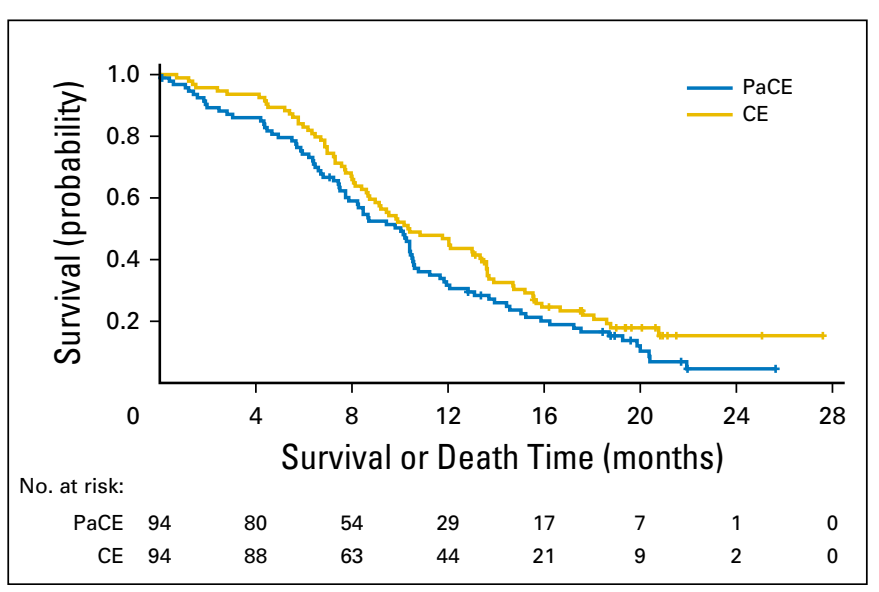

Fig 2. Kaplan-Meier curves for overall survival for intention-to-treat population. CE, carboplatin and etoposide; PaCE, palifosfamide plus CE.

only statistically significant TEAE in both treatment arms and was noted in $11 \%$ of patients on the CE arm compared with $3.3 \%$ of patients on the PaCE arm $(P=.048)$.

\section{Efficacy}

The median OS for the PaCE patients was 10.03 months (95\% CI, 7.7 to 10.5 months) compared with 10.37 months (95\% CI, 8.7 to 13.4 months) for the CE patients $(P=.096)$. The HR of 1.30 ( $95 \%$ CI, 0.95 to 1.78 ) is shown in Figure 2. The median OS followup was 10.7 months overall and 18.2 months for those 29 patients who were alive at the last assessment. There were no statistically significant differences in OS with PaCE versus CE patients according to age, sex, ECOG PS, or region of treatment except for patients age 65 years or older receiving CE who had a superior survival compared with those receiving $\mathrm{PaCE}(9.7 v 6.8$ months; $P=.044)$. Results are presented in the forest plot in Figure 3.

\section{DISCUSSION}

This randomized, controlled, open-label trial with an adaptive design failed to meet its primary end point of improving OS with the addition of palifosfamide to CE in patients with ES SCLC. The median OS with the addition of palifosfamide (PaCE) was numerically inferior to that observed on the CE arm. The addition of palifosfamide was not associated with an increase in SAEs; however, with the lack of documentation for all AEs, dose delays, or dose reductions on our study, it is difficult to make firm conclusions regarding the overall toxicity of PaCE compared with $\mathrm{CE}$. The study did not meet its accrual goal and was underpowered, but it is extremely unlikely that this would have been a positive study with full accrual. Carboplatin was given at a lower dose on the $\mathrm{PaCE}$ arm because this was found to be the safe dose in the phase I study, and it is unlikely that this lower dose had an impact on OS with the PaCE regimen. This study failed to confirm or reproduce the small improvement in OS observed on the Hoosier Oncology Group study that tested the addition of ifosfamide to CE. ${ }^{5}$ Further chemotherapy strategies are being evaluated in the first-line setting of ES SCLC, but it remains unknown whether any will improve outcomes over platinum doublet chemotherapy. Other strategies being evaluated in the maintenance setting after platinum doublet therapy in ES SCLC include maintenance sunitinib, which improved PFS by 1.5 months but not OS. ${ }^{13}$ In addition, pembrolizumab and nivolumab (humanized antibodies targeting the programmed cell death-1 [PD-1] receptor) are undergoing evaluation in the maintenance setting. In addition, PD- 1 inhibitors are

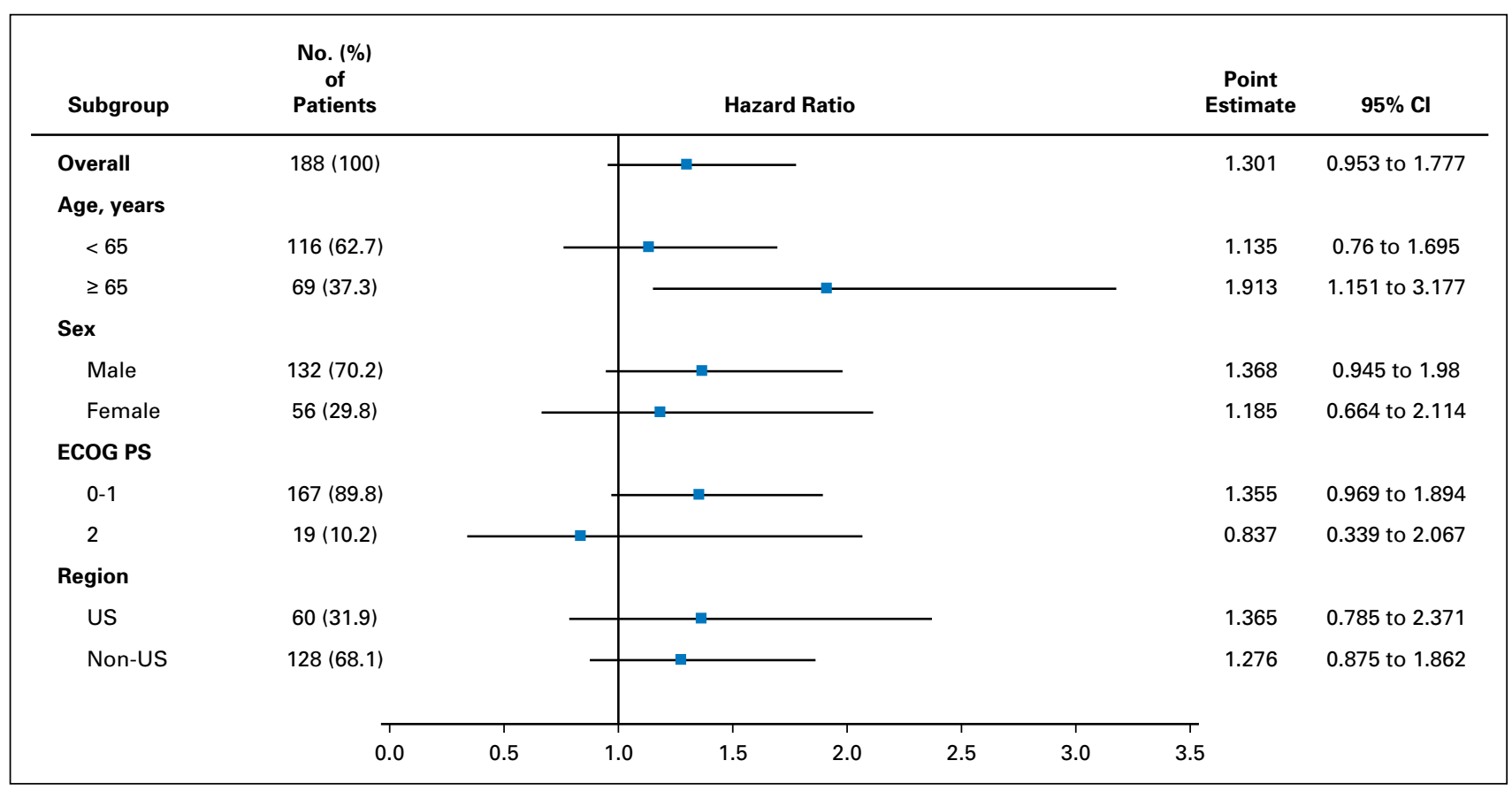

Fig 3. Forest plot of overall and subgroup hazard ratios including interactions. ECOG PS, Eastern Cooperative Oncology Group performance status. 
being combined with $\mathrm{CE}$ in the first-line setting in patients with limited-stage disease and also in the second-line setting. ${ }^{14}$

Our understanding of the biology of SCLC has significantly increased, but translating that knowledge into new clinical therapeutic options that have an impact on the care of patients with SCLC has yet to be achieved. SCLC has a high mutational burden resulting from decades of exposure to tobacco-induced carcinogens. A panel of several genes seems to be mutated or abnormal in almost all SCLCs, including p53, retinoblastoma gene, and Myc family gene members. ${ }^{14,15}$ In addition, Nfib overexpression has been shown to accelerate tumorigenesis and promote metastases in SCLC. ASCL1 is a transcription factor that is pivotal for neuroendocrine differentiation and contributes to proliferation and migration of SCLC. ${ }^{16}$ Targeting the abnormalities identified and assessing whether these approaches are effective in SCLC still need to be evaluated. Chemotherapy remains the only systemic therapy that has been shown to improve survival in ES SCLC compared with targeted therapies. Better first- and second-line treatment options for ES SCLC are necessary to transform the landscape of this bleak disease.

\section{AUTHORS' DISCLOSURES OF POTENTIAL CONFLICTS} OF INTEREST

Disclosures provided by the authors are available with this article at jco.org.

\section{AUTHOR CONTRIBUTIONS}

Conception and design: Philip Lavin, Lawrence Einhorn

Collection and assembly of data: Shadia I. Jalal, Philip Lavin, Gregory Lo, Francois Lebel

Data analysis and interpretation: All authors

Manuscript writing: All authors

Final approval of manuscript: All authors

Accountable for all aspects of the work: All authors

\section{REFERENCES}

1. Lally BE, Urbanic JJ, Blackstock AW, et al: Small cell lung cancer: Have we made any progress over the last 25 years? Oncologist 12:1096-1104, 2007

2. Noda K, Nishiwaki $Y$, Kawahara $M$, et al: Irinotecan plus cisplatin compared with etoposide plus cisplatin for extensive small-cell lung cancer. N Engl J Med 346:85-91, 2002

3. Chan BA, Coward JI: Chemotherapy advances in small-cell lung cancer. J Thorac Dis 5:S565-S578, 2013

4. Ettinger DS, Finkelstein DM, Sarma RP, et al: Phase II study of paclitaxel in patients with extensivedisease small-cell lung cancer: An Eastern Cooperative Oncology Group study. J Clin Oncol 13: 1430-1435, 1995

5. Loehrer PJ Sr, Ansari R, Gonin R, et al: Cisplatin plus etoposide with and without ifosfamide in extensive small-cell lung cancer: A Hoosier Oncology Group study. J Clin Oncol 13:2594-2599, 1995

6. Tascilar M, Loos WJ, Seynaeve C, et al: The pharmacologic basis of ifosfamide use in adult patients with advanced soft tissue sarcomas. Oncologist 12:1351-1360, 2007

7. Ludeman SM, Gamcsik MP: Mechanisms of resistance against cyclophosphamide and ifosfamide: Can they be overcome without sacrificing selectivity? Cancer Treat Res 112:177-197, 2002

8. Struck RF, Dykes DJ, Corbett TH, et al: Isophosphoramide mustard, a metabolite of ifosfamide with activity against murine tumours comparable to cyclophosphamide. Br J Cancer 47:15-26, 1983

9. Hingorani $P$, Zhang W, Piperdi S, et al: Preclinical activity of palifosfamide lysine (ZIO-201) in pediatric sarcomas including oxazaphosphorineresistant osteosarcoma. Cancer Chemother Pharmacol 64:733-740, 2009

10. Harb WA, Ramaswamy G, Fisher WB, et al: Multicenter phase lb study of the safety and efficacy of palifosfamide plus carboplatin/etoposide (PaCE) in patients with small cell lung cancer or other selected cancer. Mol Cancer Ther 10, 2011 (suppl: abstr B53)

11. Somaiah N, von Mehren M: New drugs and combinations for the treatment of soft-tissue sarcoma: A review. Cancer Manag Res 4:397-411, 2012
12. Ryan $C W$, Merimsky $O$, Agulnik $M$, et al: PICASSO III: A phase III, placebo-controlled study of doxorubicin with or without palifosfamide in patients with metastatic soft tissue sarcoma. J Clin Oncol [epub ahead of print on September 12, 2016]

13. Ready NE, Pang HH, Gu L, et al: Chemotherapy with or without maintenance sunitinib for untreated extensive-stage small-cell lung cancer: A randomized, double-blind, placebo-controlled phase II study-CALGB 30504 (Alliance). J Clin Oncol 33: 1660-1665, 2015

14. Bunn PA Jr, Minna JD, Augustyn A, et al: Small cell lung cancer: Can recent advances in biology and molecular biology be translated into improved outcomes? J Thorac Oncol 11:453-474, 2016

15. Rekhtman N, Pietanza MC, Hellmann MD, et al: Next-generation sequencing of pulmonary large cell neuroendocrine carcinoma reveals small cell carcinoma-like and non-small cell carcinoma-like subsets. Clin Cancer Res 22: 3618-3629, 2016

16. Karachaliou N, Pilotto S, Lazzari C, et al: Cellular and molecular biology of small cell lung cancer: An overview. Transl Lung Cancer Res 5:2-15, 2016

\section{Affiliations}

Shadia I. Jalal and Lawrence Einhorn, Indiana University School of Medicine and Indiana University Melvin and Bren Simon Cancer Center, Indianapolis, IN; Philip Lavin, Lavin Consulting, Framingham; Francois Lebel, ZIOPHARM Oncology, Boston, MA; and Gregory Lo, R.S. McLaughlin Durham Regional Cancer Center at Lakeridge Health Oshawa, Oshawa, ON, Canada.

Supported by ZIOPHARM Oncology.

\section{Support}

\section{Prior Presentation}

Presented at the 51st Annual Meeting of the American Society of Clinical Oncology, Chicago, IL, May 29-June 2, 2015. 
Carboplatin and Etoposide With or Without Palifosfamide in Untreated Extensive-Stage Small-Cell Lung Cancer: A Multicenter, Adaptive, Randomized Phase III Study (MATISSE)

The following represents disclosure information provided by authors of this manuscript. All relationships are considered compensated. Relationships are self-held unless noted. I = Immediate Family Member, Inst = My Institution. Relationships may not relate to the subject matter of this manuscript. For more information about ASCO's conflict of interest policy, please refer to www.asco.org/rwc or ascopubs.org/jco/site/ifc.

Shadia I. Jalal

Research Funding: AstraZeneca, MedImmune

Philip Lavin

Consulting or Advisory Role: ZIOPHARM Oncology

Gregory Lo

No relationship to disclose

\section{Francois Lebel}

Employment: ZIOPHARM Oncology

Leadership: ZIOPHARM Oncology

Stock or Other Ownership: ZIOPHARM Oncology

Honoraria: ZIOPHARM Oncology

Research Funding: ZIOPHARM Oncology

Travel, Accommodations, Expenses: ZIOPHARM Oncology

Lawrence Einhorn

Stock or Other Ownership: Amgen, Biogen Idec

Consulting or Advisory Role: Celgene 


\section{Appendix}

Table A1. Sites for the MATISSE (Multicenter Adaptive Trial Investigating Small Cell Lung Cancer Survival Endpoints) Study

\begin{tabular}{|c|c|c|}
\hline Country/State/Province & City & Institution \\
\hline \multicolumn{3}{|l|}{ United States } \\
\hline Alabama & Birmingham & Birmingham Hematology and Oncology Associates \\
\hline \multirow[t]{2}{*}{ California } & Los Angeles & University of Southern California \\
\hline & Santa Rosa & Redwood Regional Oncology Group \\
\hline Delaware & Newark & Christiana Care Health Services \\
\hline \multirow[t]{2}{*}{ Florida } & Jacksonville & Baptist Cancer Institute \\
\hline & Port St. Lucie & Hematology Oncology Associates of the Treasure Coast \\
\hline Georgia & Atlanta & Peachtree Hematology Oncology Consultants \\
\hline \multirow[t]{3}{*}{ Illinois } & Chicago & Rush University Medical Center \\
\hline & Galesburg & Medical and Surgical Specialists \\
\hline & Niles & Illinois Cancer Specialists \\
\hline \multirow[t]{5}{*}{ Indiana } & Fishers & Central Indiana Cancer Centers \\
\hline & Goshen & Goshen Center for Cancer Care \\
\hline & Indianapolis & Indiana University \\
\hline & Lafayette & Horizon Oncology Center \\
\hline & Muncie & Indiana University Health Ball Memorial Hospital \\
\hline Kansas & Overland Park & University of Kansas Hospital \\
\hline Kentucky & Lexington & Central Baptist Hospital \\
\hline Louisiana & Baton Rouge & Medical Oncology \\
\hline Maryland & Frederick & Frederick Memorial Hospital Regional Cancer Therapy Center \\
\hline Michigan & Wyoming & Metro Health Cancer Center \\
\hline \multirow[t]{2}{*}{ Minnesota } & Duluth & Saint Mary's Medical Center \\
\hline & Minneapolis & Virginia Piper Cancer Institute \\
\hline \multirow[t]{2}{*}{ New Jersey } & Hackensack & $\begin{array}{l}\text { John Theurer Cancer Center at Hackensack University Medical } \\
\text { Center }\end{array}$ \\
\hline & Morristown & $\begin{array}{l}\text { Hematology Oncology Associates of Northern New Jersey; } \\
\text { Carol G. Simon Cancer Center }\end{array}$ \\
\hline New Mexico & Albuquerque & University of New Mexico Cancer Center \\
\hline \multirow[t]{2}{*}{ New York } & Albany & New York Oncology Hematology \\
\hline & New York City & Montefiore Medical Center \\
\hline \multirow[t]{2}{*}{ Ohio } & Cincinnati & The Christ Hospital \\
\hline & Dayton & $\begin{array}{l}\text { Greater Dayton Cancer Center, Medical Oncology Hematology } \\
\text { Associates }\end{array}$ \\
\hline Pennsylvania & Kingston & Medical Oncology Associates of Wyoming Valley \\
\hline South Carolina & Charleston & Charleston Hematology Oncology Associates \\
\hline \multirow[t]{5}{*}{ Texas } & Dallas & Texas Oncology-Medical City Dallas \\
\hline & Dallas & Texas Oncology-Baylor, Charles A. Sammons Cancer Center \\
\hline & Galveston & University of Texas Medical Branch at Galveston \\
\hline & Houston & Oncology Consultants \\
\hline & Wichita Falls & Texas Oncology \\
\hline Vermont & Burlington & University of Vermont Medical Center \\
\hline Virginia & Fairfax & Fairfax Northern Virginia Hematology-Oncology \\
\hline Washington & Seattle & Swedish Medical Center \\
\hline Wisconsin & Madison & Wisconsin Institutes for Medical Research \\
\hline \multicolumn{3}{|l|}{ Australia } \\
\hline New South Wales & Wollongong & Southern Medical Day Oncology Care Centre \\
\hline \multicolumn{3}{|r|}{ 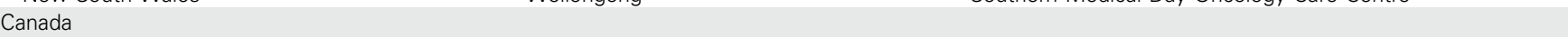 } \\
\hline Manitoba & Winnipeg & CancerCare Manitoba \\
\hline Ontario & Oshawa & $\begin{array}{l}\text { R.S. McLaughlin Durham Regional Cancer Center at Lakeridge } \\
\text { Health Oshawa }\end{array}$ \\
\hline Quebec & Sainte-Foy & Hôpital Laval \\
\hline \multicolumn{3}{|l|}{ France } \\
\hline Normandie & Caen & Centre François Baclesse \\
\hline Bretagne & Brest & Centre Hospitalier Universitaire-Hôpital Morvan \\
\hline Centre-Val de Loire & Tours & Centre Hospitalier Universitaire, Hopital Bretonneau \\
\hline Lorraine & Limoges & Hôpital du Cluzeau \\
\hline Pays de la Loire & Saint-Herblain & Institut de Cancérologie de I'Ouest-René Gauducheau \\
\hline Cote d'Azur-Corse & Marseille & Hôpital Saint Joseph \\
\hline \multirow[t]{3}{*}{ Rhône -Alpes } & Pierre Bénité & Centre Hospitalier Lyon Sud \\
\hline & Strasbourg & Centre Paul Strauss \\
\hline & (continued on following page) & \\
\hline
\end{tabular}


Table A1. Sites for the MATISSE (Multicenter Adaptive Trial Investigating Small Cell Lung Cancer Survival Endpoints) Study (continued)

\begin{tabular}{|c|c|c|}
\hline Country/State/Province & City & Institution \\
\hline \multicolumn{3}{|l|}{ Hungary } \\
\hline Hajdu-bihar & Debrecen & Debreceni Egyetem Orvos és Egészségtudományi Centrum \\
\hline Heves & Mátraháza & Mátrai Gyógyintézet \\
\hline \multirow[t]{3}{*}{ Israel } & Haifa & Rambam Medical Center \\
\hline & Jerusalem & Hadassah Medical Organization, Ein Kerem \\
\hline & Kfar Saba & Meir Hospital Sapir Medical Center \\
\hline \multirow[t]{3}{*}{ Italy } & Genova & Istituto Nazionale per la Ricerca sul Cancro \\
\hline & Milano & Azienda Ospedaliera Ospedale Niguarda Ca' Granda \\
\hline & Trento & Presidio Ospedaliero S. Chiara \\
\hline \multicolumn{3}{|r|}{ 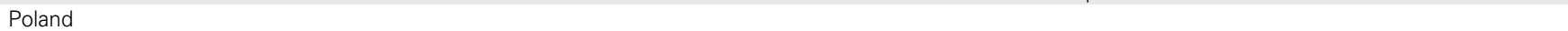 } \\
\hline Mazowieckie & Warszawa & $\begin{array}{l}\text { Centrum Onkologii-Instytut im. M. Sklodowskiej-Curie w } \\
\text { Warszawie }\end{array}$ \\
\hline \multicolumn{3}{|l|}{ Russian Federation } \\
\hline Bashkortostan & Ufa & $\begin{array}{l}\text { Republic Clinical Oncology Dispensary of the Ministry of } \\
\text { Healthcare of Republic of Bashkortostan }\end{array}$ \\
\hline Moscow Region & Moscow & City Oncology Hospital \# 62 \\
\hline Primorsky & Arkhangelsk & $\begin{array}{l}\text { State Institution of Healthcare "Arkhangelsk Regional Clinical } \\
\text { Oncology Dispensary" }\end{array}$ \\
\hline \multirow[t]{4}{*}{ Tatarstan } & Kazan & $\begin{array}{l}\text { Republican Clinical Oncologic Dispensary of Ministry of Health } \\
\text { of Republic Tatarstan }\end{array}$ \\
\hline & Chelaybinsk & $\begin{array}{l}\text { State Budget Institution of Healthcare "Chelyabinsk Regional } \\
\text { Clinical Oncology Dispensary" }\end{array}$ \\
\hline & Ivanovo & Ivanovo Regional Oncology Centre \\
\hline & Moscow & Cancer Research Center n.a. N.N. Blokhin \\
\hline \multirow[t]{3}{*}{ Nizhny Novgorod } & & Nizhnij Novgorod City Oncology Dispensary \\
\hline & St. Petersburg & $\begin{array}{l}\text { State Educational Institution "S.M. Kirov Military Medical } \\
\text { Academy of Ministry of Defense of Russia" }\end{array}$ \\
\hline & St. Petersburg & St. Petersburg State I.P. Pavlov Medical University \\
\hline Yaroslavl & & $\begin{array}{l}\text { State Healthcare Institution of Yaroslavl region "Regional } \\
\text { Clinical Oncologic Hospital" }\end{array}$ \\
\hline Taiwan & Taichung & China Medical University Hospital \\
\hline United Kingdom & Manchester & Wythenshawe Hospital \\
\hline
\end{tabular}

